\title{
CARACTERIZACIÓN ENERGÉTICA Y PROTEICA DE MATERIAS PRIMAS DE ORIGEN ANIMAL, EMPLEADAS EN LA FORMULACIÓN DE ALIMENTOS BALANCEADOS PARA VACAS LECHERAS1
}

\author{
Carlos Boschini Figueroa ${ }^{2}$, Jorge Elizondo Salazar 2,3
}

\begin{abstract}
RESUMEN
Caracterización energética y proteica de materias primas de origen animal empleadas en la formulación de alimentos balanceados para vacas lecheras. Se determinó la cinética de la degradación ruminal de la materia seca, la proteína cruda y el extracto etéreo en las harinas de pescado, carne y hueso y tortave. Con base en los resultados de degradación a 48 horas de incubación ruminal, se determinó en forma biológica los contenidos digeribles reales de la proteína y grasa digerida, haciendo más precisa la medición del total de nutrientes digeribles y los valores de energía digestible y neta de los alimentos que por el método químico. Los valores de energía neta para producción fueron de 2,02, 1,66 y 2,60 Mcals/kg en la harina de pescado, harina de carne y hueso y la tortave, respectivamente. La fracción de proteína soluble (A) fue alta en la harina de pescado $(75,29 \%)$, media en la harina de carne y hueso $(46,83 \%)$ y más baja en la harina de tortave $(25,75 \%)$, con una fracción degradable (B) de 10,62, 27,66 y 42,06\%; así como una fracción insoluble (C) de $14,09,25,51$, y $32,19 \%$, respectivamente. La proteína degradada en el rumen fue de $83,23,66,25$ y $51,98 \%$, en el mismo orden de presentación anterior. Los contenidos de proteína cruda efectivamente retenida por el animal durante el proceso de digestión total, fueron de 53,29, 51,86 y 42,05\% para la harina de pescado, harina de carne y hueso y la harina de tortave.
\end{abstract}

Palabras clave: Energía neta, proteína verdadera, materias primas, origen animal.

\begin{abstract}
Energetic and proteic characterization of prime sources of animal origin used in the formulation of a balanced feed for dairy cattle. The kinetics of ruminal degradation of dry matter, crude protein and ether extract were determined for fish, meat and bone, and poultry meals. These meals of animal origin showed characteristics proper of the species of origin, not only in the soluble fraction but also in the rates of ruminal degradability of the potentially degradable fraction. Based on the results of degradation after 48 hours of ruminal incubation, the true digestible contents of the protein and the digested ether extract were determined biologically, making the measurement of the total digestible nutrients, and the concentration and net rate of digestible energy and feed, more precise than determinations by chemical methods. The concentrations of energy for milk production was 2.02, 1.66, and $2.60 \mathrm{Mcals} / \mathrm{kg}$ for fish, meat and bone, and poultry meals, respectively. The fraction of soluble protein (A) was high in fish meal (75.29\%), intermediate in meat and bone (46.83\%), and low in poultry $(25.75 \%)$, with a degradable fraction (B) of $10.62,27.66$, and $42.06 \%$, along with an insoluble fraction (C) of $14.09,25.51$, and $32.19 \%$, respectively. The degraded protein in the rumen was $83.23,66.25$, and $51.98 \%$ in the same order cited above. The contents of crude protein effectively retained by the animals during the whole digestive process were $53.29,51.86$, and $42.05 \%$ for fish, meat and bone and poultry meals, respectively.
\end{abstract}

Key words: Net energy, true protein, animal feeds, animal source.

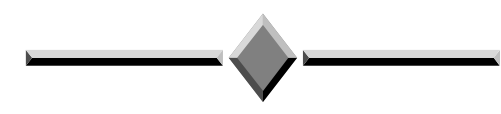

\section{INTRODUCCIÓN}

Las vacas de alta producción lechera requieren una dieta total con alta concentración de energía y proteína
(NRC 1989). Las materias primas de origen animal enriquecen ambos nutrientes en las mezclas de alimentos por lo que su uso es frecuente. En Costa Rica, las fábricas de alimentos concentrados agregaron por

\footnotetext{
1 Recibido: 14 de octubre, 2004. Aceptado: 30 de agosto, 2005. Inscrito en la Vicerrectoría de Investigación de la Universidad de Costa Rica, Proyecto No. 737-A0-046.

2 Estación Experimental Alfredo Volio Mata. Facultad de Ciencias Agroalimentarias. Universidad de Costa Rica. Correo electrónico: boschini@cariari.ucr.ac.cr.

3 Animal Science, Penn State University, USA.
} 
muchos años, tres ingredientes básicos: la tortave, la harina de carne y hueso y la harina de pescado, en proporciones adecuadas al balance de la mezcla, aunque en la actualidad la legislación costarricense prohíbe el uso de la harina de carne y de torta ave en alimentos para bovinos, pero no así en otros países.

La tortave es un subproducto de la industria nacional avícola, derivado del proceso de matanza, en la cual las plumas son hidrolizadas previamente al proceso de mezclado con vísceras, cabeza, patas y partes grasosas. Posteriormente, sobreviene el proceso de cocido y secado, estabilización y molienda. La harina de carne y hueso es el residuo de tejidos animales y huesos obtenida principalmente por proceso de derretimiento, tiene un contenido de proteína semejante a la harina de pescado. Esta última, proviene grandemente de la pesca de anchoveta entera aunque en la actualidad la legislación costarricense prohíbe el uso de la harina de carne y de torta ave en alimentos para bovinos, pero no así en otros países que se reduce a harina de pescado, eliminando la mayor parte de agua, conservando la proteína por cocimiento al vapor, formación de una torta por prensado, liberación de aceite, secado y molido (Rojas 1971; Jurgens 2002).

No se cuenta con antecedentes sobre la cinética ruminal de la materia seca en esas fuentes, ni sobre la degradabilidad ruminal de la proteína o la grasa contenida. El NRC (2001) reporta valores de proteína cruda entre 54 y $57 \%$ y de 10 a $13 \%$ de extracto etéreo en la harina de carne y hueso. En la harina de pescado se reportan valores entre 68 y $71 \%$ de proteína cruda, con una fracción soluble de 23 a 32\%, la fracción degradable entre 38 y $72 \%$ y la proteína indegradable de 17 a $30 \%$, dependiendo del proceso industrial empleado. Como fuente de aminoácidos, la harina de pescado, es superior a las otras dos fuentes cuando se emplea en la alimentación de monogástricos; sin embargo, en rumiantes, con un valor de proteína indegradable inferior a 30\%, es moderada la contribución de proteína sobrepasante en la mezcla concentrada. Las harinas de origen animal, son altas en fósforo y calcio, buenas fuentes de vitamina $B_{12}$ y por lo general bajas en vitamina A. La harina de pescado en particular es rica en metionina y triptofano (Piccioni 1970).

Nuestras industrias de alimentos balanceados para rumiantes emplean las harinas de origen animal, aportando proteína y energía a las mezclas. A partir del 2001, las necesidades energéticas y proteicas establecidas por el National Research Council de los EE.UU obligan a conocer el valor energético neto de los alimentos y el fraccionamiento de la proteína. Por tal razón, el presente trabajo tuvo el propósito de estudiar la degradabilidad ruminal de la materia seca, la proteína

ISSN: 1021-7444 cruda y el extracto etéreo en tres materias primas de origen animal, así como el contenido de energía neta para mantenimiento, crecimiento y producción de leche, el fraccionamiento de la proteína del alimento y las proporciones de proteína verdadera, degradable e indegradable esperadas, mediante un método químico y otro biológico.

\section{MATERIALES Y MÉTODOS}

El estudio se llevó a cabo en la Estación Experimental "Alfredo Volio Mata" de la Universidad de Costa Rica, ubicada en la provincia de Cartago, a partir de marzo del 2004. Las harinas de tortave, pescado y carne y hueso se obtuvieron en una fábrica nacional de alimentos balanceados.

Se determinó la composición química proximal mediante los procedimientos de la A.O.A.C. (2002), para caracterizar cada materia prima. Posteriormente, éstas fueron preparadas para el proceso de degradación ruminal, siguiendo la técnica descrita por Orskov (1984) en bolsas de nylon. Se usaron bolsas Ankon ${ }^{\circledR}$ de $10 \times 20 \mathrm{~cm}$ con un poro de $53 \mu \mathrm{m}$ de diámetro, conteniendo cada una $5 \mathrm{~g}$ de muestra secada a $105^{\circ} \mathrm{C}$, con el tamaño de granulación tal como fue suministrada por el proveedor. Las bolsas de nylon fueron suspendidas en el rumen de dos vacas fistuladas ruminalmente, mantenidas con una dieta forrajera de pasto Estrella Africana (Cynodon nlemfluensis). Las bolsas divididas en cuatro repeticiones con 12 , 8, 4, 4, 3 y 2 observaciones por repetición en cada tiempo de incubación, fueron introducidas consecutivamente en el rumen y mantenidas por $48,24,12,6$ y 2 h, respectivamente. La desaparición a $0 \mathrm{~h}$ de incubación fue evaluada por inmersión de las bolsas en agua a $40^{\circ} \mathrm{C}$ por $1 \mathrm{~h}$. En el tiempo previsto, las bolsas fueron extraídas del rumen, y lavadas inmediatamente con agua fría en una lavadora comercial, durante un ciclo completo de lavado para remover la contaminación microbial en los residuos contenidos en las bolsas de nylon. Posteriormente, fueron secadas a $105^{\circ} \mathrm{C}$, pesadas individualmente y se unieron los residuos de las observaciones previstas en cada repetición, preparadas para los análisis de proteína cruda y extracto etéreo (A.O.A.C. 2002). Con los valores de materia seca, proteína y grasa, la cinética de la degradación fue determinada con el procedimiento descrito por Orskov y McDonald (1979). Los datos fueron ajustados a la ecuación exponencial:

$$
P=a+b\left(1-e^{-c t}\right)
$$

donde $\mathrm{P}=$ degradación después de $\mathrm{t}$ horas de incubación ruminal, $\mathrm{a}=$ fracción soluble $(\%), \mathrm{b}=$ fracción 
degradable $(\%), \mathrm{c}=$ tasa de degradación $(\% / \mathrm{h}), \mathrm{t}=$ tiempo de incubación ruminal (h).

Las constantes fueron calculadas por un programa de cuadrados mínimos iterativo, usando el algoritmo de Marquardt.

Los valores de energía neta fueron estimados siguiendo los procedimientos del NRC (2001) para alimentos de origen animal, usando las fórmulas del método químico estándar y el método biológico para determinar los valores de digestibilidad verdadera, obtenidos para proteína y grasa a 48 horas de incubación ruminal, recomendado por Yu et al. (2004). Los métodos para determinar el total de nutrientes digeribles a una vez mantenimiento, así como la energía digestible y la neta para producción, mantenimiento y crecimiento, fueron los siguientes:

1.- $d v P C=P C \times P C_{D I G} / 100 \quad$ (método químico) donde: $\mathrm{dvPC}=$ proteína cruda verdaderamente digestible $\mathrm{PC}=$ proteína cruda en el alimento

$\mathrm{PC}_{\text {DIG }}=$ digestibilidad de la proteína cruda de cada alimento [factores $\mathrm{NRC}(2001)$ para harina de pescado $=$ $95 \%$, y harina de carne y hueso $=80 \%$, tortave se usó el mismo valor de la harina de carne y hueso].

$d v P C=P C \times P C_{48 H} / 100 \quad$ (método biológico) donde: $\mathrm{PC}_{48 \mathrm{H}}=$ degradabilidad ruminal de la proteína cruda a 48 horas de incubación ruminal.

2.- $d v A G=0,90 \times(E E-1) \quad$ (método químico) donde: $\operatorname{dvAG}=$ ácidos grados verdaderamente digestibles, $\mathrm{EE}=$ extracto etéreo en el alimento.

$d v A G=E E_{48 H} x(E E-1) \quad$ (método biológico) donde: $\mathrm{EE}_{48 \mathrm{H}}=$ degradabilidad ruminal del extracto etéreo a 48 horas de incubación ruminal

3.- $d v C N F=0,98 \times(100-P C-E E-C e n)$ (método químico y biológico)

donde: $\mathrm{dvCNF}=$ carbohidratos no fibrosos verdaderamente digestibles. Cen = cenizas en el alimento.

4.- $T N D_{1 X}=d v P C+d v A G \times 2,25+d v C N F-7$

donde: $\mathrm{TND}_{1 \mathrm{X}}=$ total de nutrientes digestibles a una vez mantenimiento.

5.- $E D_{1 X}=d v C N F \times 4,2 / 100+d v P C \times 5,6 / 100+$ $d v A G \times 9,4 / 100-0,3$

donde: $\mathrm{ED}_{1 \mathrm{X}}=$ energía digestible a una vez mantenimiento.

6.- $F D=\left[T N D_{1 X \%}-\left(0,18 \times T N D_{1 X \%}-10,3\right) x\right.$ ConsTND $\left.{ }_{n X-1}\right] / T N D_{1 X \%}$ donde: $\mathrm{FD}=$ factor de descuento, en tanto por 1 (de $0 \mathrm{a}$ 1)

$\mathrm{TND}_{1 \mathrm{X}} \%=$ concentración de TND en la dieta total, $\%$

ConsTND $=$ consumo de TND sobre 1 vez mantenimiento

7.- $E D_{P}=E D_{1 X} x F D$

donde: $\mathrm{EDP}=$ energía digestible a consumo actual de producción, Mcal/kg

8.- $E M_{P}=\left(1,01 \times E D_{P}-0,45\right)+0,0046 \times(E E-3)$ donde: $\mathrm{EMP}=$ energía metabolizable para producción

9.- $E N_{P}=0,703 \times E M_{P}-0,19+\left[\left(0,097 \times E M_{P}+\right.\right.$ 0,19)/ 97] $x(E E-3)$

donde: $\mathrm{EN}_{\mathrm{P}}=$ energía neta para producción, arriba de 1 vez mantenimiento.

Para estimar la energía neta de mantenimiento y de crecimiento se usó la fórmula de energía metabolizable (EM) empleada por Garrett (1980), así:

$$
\begin{aligned}
\text { 10.- } & E N_{M}=1,37 \times E M-0,138 \times E M^{2}+0,00105 \times E M^{3} \\
& -1,12 \\
& \text { donde } \mathrm{EN}_{\mathrm{M}}=\text { energía neta para mantenimiento }
\end{aligned}
$$

11.- $E N_{C}=1,42 \times E M-0,174 \times E M^{2}+0,0122 \times E M^{3}$ $-1,12$

donde: $\mathrm{EN}_{\mathrm{C}}=$ energía neta para crecimiento

Las fracciones de proteína contenidas en los alimentos se determinaron biológicamente empleando los valores de degradación ruminal a 0 horas, como fracción A (proteína soluble) y a 48 horas, el residuo proteico como fracción C (proteína indegradable) y la fracción B (proteína degradable) como proteína total - fracción A fracción C. En la determinación de la proteína degradada en el rumen, se empleó la tasa de degradación encontrada en el ajuste de los datos al modelo de Orskov (1984), de cada materia prima, en porcentaje por hora. La velocidad de pasaje fue estimada con base en el consumo de materia seca, en porcentaje del peso vivo, para dos vacas típicas equivalentes, una de $400 \mathrm{~kg}$ de peso vivo con $20 \mathrm{~kg} /$ día de producción de leche (Jersey) y otra de $550 \mathrm{~kg}$ con $25 \mathrm{~kg} /$ día (Holstein), respectivamente. Los mismos parámetros fueron empleados en la determinación de proteína indegradable en el rumen y la fracción $\mathrm{C}$ encontrada en el residuo de la materia seca a 48 horas de incubación ruminal.

Los resultados de digestibilidad verdadera proteína y grasa y de energía fueron sometidos al análisis de varianza con un modelo anidado, la fuente principal de variación se asignó a los métodos (químico y biológico) y las materias primas estudiadas se anidaron dentro del 
efecto método (Gill 1978). Los valores de las fracciones proteicas y las proporciones de proteína degradable e indegradable fueron analizadas con un modelo de un camino de clasificación, asignado a las materias primas. El análisis estadístico se realizó con el PROC GLM de SAS (SAS 1985).

\section{RESULTADOS}

En el Cuadro 1 se presenta el análisis proximal de las tres materias primas, con diferencias en proteína ( $\mathrm{P}$ $\leq 0,05$ ) en un estrecho rango arriba de $52 \%$ de proteína cruda. El contenido de grasas fue alto, siendo muy similares la harina de pescado y la harina de carne y hueso $(P \geq 0,05)$, diferenciándose $(P \leq 0,01)$ la harina de tortave con un $19 \%$. La concentración de cenizas fue más de $25 \%$ en la harina de pescado y la harina de carne y hueso, siendo únicamente alrededor de $6 \%$ en la tortave $(\mathrm{P} \leq 0,01)$.

Cuadro 1. Composición química de materias primas de origen animal. Cartago, 2004.

\begin{tabular}{lrrr}
\hline & \multicolumn{3}{c}{ Materia primas } \\
\multicolumn{1}{c}{ Composición química } & TA & HCH & HP \\
\hline Materia seca (\%) & 89,90 & 95,90 & 90,85 \\
Proteína cruda (\%) & 52,43 & 56,52 & 54,67 \\
Fibra cruda (\%) & 1,10 & 1,10 & 0,40 \\
Extracto etéreo (\%) & 19,00 & 11,90 & 10,40 \\
Extracto libre de nitrógeno (\%) & 11,54 & 3,01 & 9,00 \\
Cenizas (\%) & 15,93 & 27,47 & 25,53 \\
\hline
\end{tabular}

TA: tortave, HCH: harina de carne y hueso, HP: harina de pescado.

La cinética de la degradabilidad ruminal de la materia seca contenida en las harinas se muestra en la Figura 1. La fracción soluble $(\mathrm{P}<0,01)$ representa dos terceras partes en la harina de pescado, una cuarta parte en la harina de tortave y una quinta parte en la harina de carne y hueso. La restante fracción insoluble es degradable en el rumen $(P \leq 0,01)$ en alrededor de una séptima parte de la materia seca en la harina de pescado, una cuarta parte en la harina de carne y hueso y la mitad de la harina de tortave, a tasas de desaparición $(\mathrm{P} \leq 0,01)$ de $17,88,13,81$ y $5,28 \% / \mathrm{h}$, respectivamente.

La degradación ruminal de las proteínas se muestran en la Figura 2. El 75\% de ellas son solubles en la harina de pescado contra un 46 y $25 \%$ en la harina de carne y hueso y en la harina de tortave, respectivamente. La porción restante de proteínas es potencialmente

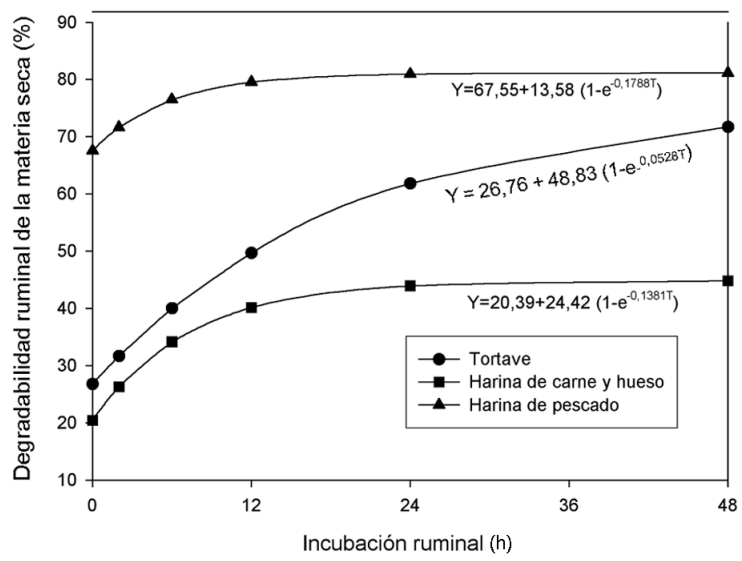

Figura 1. Curvas de degradabilidad ruminal de la materia seca en tres materias primas de origen animal. Cartago, 2004.

degradable en el rumen en $10,62,27,70$ y $43,74 \%$, en el orden presentado previamente. Estas fracciones, se degradaron $(P \leq 0,01)$ a una velocidad de 17,84 y $14,22 \% / \mathrm{h}$ en la harina de pescado y la harina de carne y hueso, respectivamente, y más lentamente en la harina de tortave con una tasa de $6,78 \% / \mathrm{h}$. A 48 horas de incubación ruminal se degradó $(\mathrm{P} \leq 0,01)$ el 85,91\% de la proteína contenida en la harina de pescado, el $74,49 \%$ contenida en la harina de carne y hueso y el $67,81 \%$ de proteína presente en la harina de tortave.

La curvas de degradación ruminal del extracto etéreo se presentan en la Figura 3. Se encontraron en la fracción soluble el $93 \%$ de la grasa contenida en la harina de pescado y un 72 y $43 \%$ de la grasa contenida en

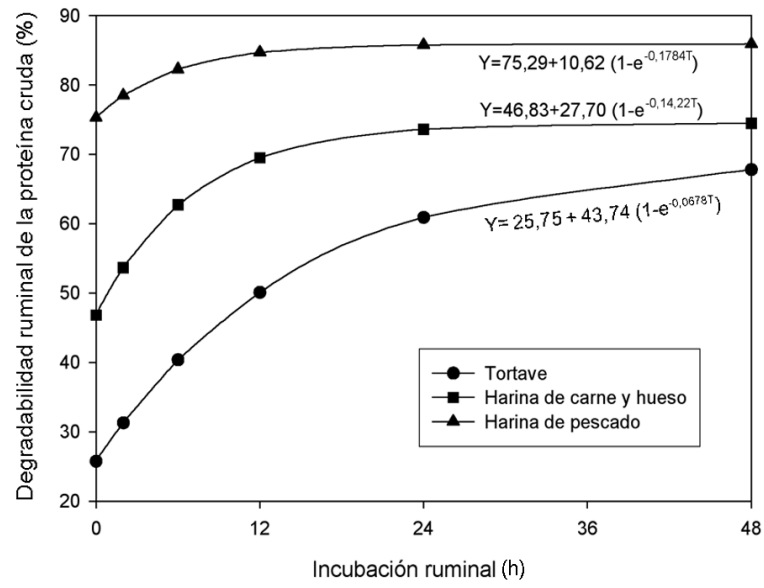

Figura 2. Curvas de degradabilidad ruminal de la proteína cruda en tres materias primas de origen animal. Cartago, 2004. 


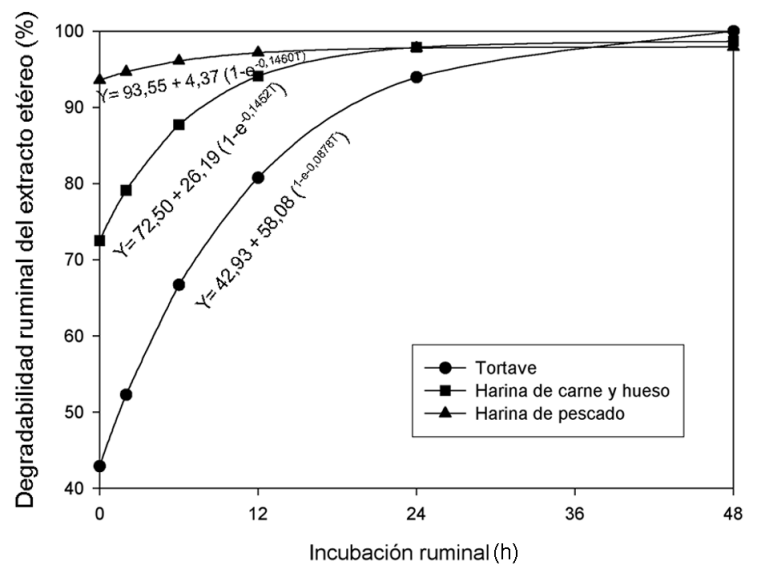

Figura 3. Curvas de degradabilidad ruminal del extracto etéreo en tres materias primas de origen animal. Cartago, 2004.

las harinas de carne y hueso y de tortave $(\mathrm{P} \leq 0,01)$. La fracción de extracto etéreo potencialmente degradable en el rumen fue menor a $5 \%$ en la harina de pescado, $26 \%$ en la harina de carne y hueso y $58 \%$ en la harina de tortave $(\mathrm{P} \leq 0,01)$, con tasas de desaparición ruminal a razón de 14,60,14,52 y $8,78 \% / \mathrm{h}$, respectivamente. A 48 horas de incubación ruminal fue degradado el 97,91, 98,67 y $100 \%$ del extracto etéreo contenido en las materias primas, en el orden presentado anteriormente.
Los valores de energía digestible y neta, total de nutrientes digestibles, proteína, grasa y carbohidratos no fibrosos digeridos, encontrados para las materias primas por el método químico y el biológico, se muestran en el Cuadro 2. Las diferencias entre métodos fueron importantes $(\mathrm{P} \leq 0,01)$ en la determinación del contenido de proteína y grasa digerida $(\mathrm{P} \leq 0,05)$, total de nutrientes digeridos, energía digestible y neta a una vez mantenimiento y para producción $(\mathrm{P} \leq 0,01)$. Las variaciones en energías para mantenimiento y crecimiento fueron importantes $(\mathrm{P} \leq 0,05)$ entre métodos. Sin considerar el método de determinación, la mayor concentración de energía neta para producción se encontró en la harina de tortave con 2,6 mcal $/ \mathrm{kg}$, luego en la harina de pescado con $2,02 \mathrm{mcal} / \mathrm{kg}$ y la menor en la harina de carne y hueso con $1,66 \mathrm{Mcal} / \mathrm{kg}$.

Las fracciones proteicas de las materias primas y las proporciones de proteína degradada e indegradada en el rumen se muestra en el Cuadro 3, empleando el método biológico. Se observaron diferencias $(\mathrm{P} \leq 0,01)$ entre las proporciones de las fracciones A (soluble), B (insoluble degradable) y C (insoluble e indegradable) entre las materias primas, así como en las proporciones de proteína degradada e indegradada en rumen en cada una de ellas. La harina de pescado mostró el mayor contenido de proteína degradada en el rumen con $83 \%$, luego la harina de carne y hueso con $66 \%$ y un $48 \%$ en la harina de tortave, siendo indigerida en el rumen un 17,34 y $52 \%$, respectivamente.

Cuadro 2. Valoración de la proteína, la grasa y la energía contenida en las materias primas estudiadas. Cartago, 2004.

\begin{tabular}{|c|c|c|c|c|c|c|}
\hline \multirow[b]{2}{*}{ Itemes estudiados } & \multicolumn{3}{|c|}{ Método químico1 } & \multicolumn{3}{|c|}{ Método químico-biológico } \\
\hline & TA & HCH & HP & TA & HCH & HP \\
\hline Digestibilidad de la proteína (\%) & 80,00 & 80,00 & 94,00 & 67,81 & 74,49 & 85,91 \\
\hline Proteína digerida $(\%)$ & 41,94 & 45,22 & 51,39 & 35,55 & 38,33 & 46,97 \\
\hline Digestibilidad de la grasa (\%) & 90,00 & 90,00 & 90,00 & 100,00 & 98,67 & 97,91 \\
\hline Grasa digerida $(\%)$ & 17,10 & 10,71 & 9,36 & 19,00 & 11,74 & 10,18 \\
\hline Carbohidratos no fibrosos digeridos $(\%)$ & 22,19 & 4,03 & 9,21 & 22,19 & 4,03 & 9,21 \\
\hline Total de nutrientes digeribles $1 \mathrm{X}^{2}(\%)$ & 95,61 & 66,34 & 67,01 & 93,49 & 61,77 & 72,09 \\
\hline Energía digestible $1 \mathrm{X}$ & 4,59 & 3,41 & 3,42 & 4,41 & 3,12 & 3,67 \\
\hline Energía neta para mantenimiento (Mcals/kg) & 2,68 & 1,61 & 1,64 & 2,60 & 1,43 & 1,83 \\
\hline Energía neta para crecimiento (Mcals/kg) & 2,44 & 1,54 & 1,56 & 2,38 & 1,37 & 1,73 \\
\hline Enegía digestible para producción $3 ; 4$ (Mcals/kg) & 4,34 & 3,22 & 3,23 & 4,17 & 2,95 & 3,47 \\
\hline Energía metabolizable para producción 4 (Mcals/kg) & 3,93 & 2,80 & 2,81 & 3,83 & 2,57 & 3,09 \\
\hline Energía neta para producción ${ }^{4}$ (Mcals/kg) & 2,57 & 1,78 & 1,79 & 2,60 & 1,66 & 2,02 \\
\hline
\end{tabular}

TA tortave, HCH harina de carne y hueso, HP harina de pescado.

1 Digestibilidad de la proteína y de la grasa tomados del NRC 2001.

$21 \mathrm{X}$ consumo a una vez mantenimiento.

3 Factor de descuento fue de 0,945, para vacas Jersey de $400 \mathrm{~kg}$ y $20 \mathrm{~kg} /$ día o vacas Holstein de $550 \mathrm{~kg}$ de peso vivo y $25 \mathrm{~kg} /$ día de producción de leche.

4 Consumo a tres veces mantenimiento. 
Cuadro 3. Fracciones proteícas en los alimentos estudiados y proporción degradable en el rumen. Cartago, 2004.

\begin{tabular}{lrrr}
\hline \multicolumn{1}{c}{ Itemes estudiados } & TA & HCH & HP \\
\hline Fracción soluble (A), \% & 25,75 & 46,83 & 75,29 \\
Fracción degradable (B), \% & 42,06 & 27,66 & 10,62 \\
Fracción insoluble (C), \% & 32,19 & 25,51 & 14,09 \\
Tasa de degradación ruminal Kd (\%/h) & 6,78 & 14,22 & 17,84 \\
$\begin{array}{l}\text { Proteína degradable en el rumen } \\
\text { (PDR) }\end{array}$ & & & \\
$\begin{array}{l}\text { Proteína indegradable en el rumen } \\
\text { (PIR) }\end{array}$ & 48,02 & 66,25 & 83,23 \\
& 51,98 & 33,75 & 16,77 \\
\hline
\end{tabular}

$\mathrm{TA}=$ tortave, $\mathrm{HCH}=$ harina de carne $\mathrm{y}$ hueso, $\mathrm{HP}=$ harina de pescado.

1 Velocidad de pasaje del alimento $\mathrm{Kp}=6,029 \% / \mathrm{h}$, para un consumo de materia seca total equivalente a $3 \%$ del peso vivo y $50 \%$ de inclusión en la dieta total.

\section{DISCUSIÓN}

En la literatura se reportan valores de proteína cruda superiores a $65 \%$ en la harina de pescado proveniente de la anchoveta y valores cercanos en la harina de carne y hueso, con extractos etéreos inferiores a $12 \%$ en ambas fuentes, similares a las materias primas estudiadas. En harinas de subproductos de pollo (vísceras, patas y cabezas) se reportan valores de $61 \%$ de proteína cruda y $13 \%$ de extracto etéreo (NRC 2001; Jurgens 2002), diferentes a la concentración de ambos nutrientes contenidos en la tortave estudiada.

La harina de pescado mostró una fracción de materia seca soluble muy alta en comparación con los valores de las harinas carne y hueso y de tortave. Se observó que la máxima degradación ruminal de la materia seca se alcanzó en un periodo cercano a las 12 horas de incubación in situ, no obstante la harina de tortave no logró mostrar esta misma respuesta a las 48 horas, manteniendo residuos de materia seca potencialmente degradables por un periodo mayor, dada comparativamente la baja tasa relativa de desaparición ruminal .

A pesar de contener las tres materias primas valores de proteína cruda entre 52 y $56 \%$, el origen animal de ellas se muestra en una fracción soluble muy diferenciada para cada una, con tasas cercanas de desaparición ruminal en las harinas de pescado y carne y hueso. De nuevo, se observa en ellas que a las 12 horas de incubación ruminal, están próximas a alcanzar la desaparición ruminal máxima de proteína cruda potencialmente degradable. La proteína de la harina de tortave, a las 48 horas de degradación in situ, aún no alcanzó la asíntota de degradabilidad potencial. Nuevamente se observa en esa materia prima que la tasa de degradación es menor al 50\% de la cuantificada en las otras dos.

En el Cuadro 1 se observa que la concentración de extracto etéreo en la harina de tortave es más de $80 \%$ superior $(\mathrm{P} \leq 0,05)$ a la encontrada en las harinas de pescado y carne y hueso. En la fracción soluble de grasa se muestra las diferencias del origen animal de cada una de ellas y de los procesos industriales recibidos. Cercano a las 24 horas de degradación ruminal, los ácidos grasos de la harina de pescado y de carne y hueso alcanzan el mismo valor de degradación potencial in si$t u$, mientras que en la harina de tortave fue máxima a las 48 horas (100\%).

El método biológico mostró variaciones amplias en la digestibilidad de las proteínas y de las grasas con respecto a las recomendadas por el NRC (2001). En el caso de la proteínas, las digestibilidades reportadas por el NRC (2001) para ser empleadas como factores en el método químico fueron superiores en todos los casos a los determinados por el método biológico, en $8 \%$ para la harina de pescado, $5 \%$ para la harina de carne y hueso y $12 \%$ en el caso de la harina de tortave. En el caso de la digestibilidad de los ácidos grasos, el NRC (2001) recomienda valores de 90 y 95\% para el método químico, a pesar de la diferente composición de los ácidos grasos en las materias primas estudiadas. En la harina de pescado, las grasas se presentan altamente insaturada y polinsaturada, mientras que en la harina de carne más del $50 \%$ de la grasa está en forma saturada. En la torta de ave hay una mezcla intermedia de grasas saturadas e insaturadas. Por el método biológico, las digestibilidades encontradas fueron iguales o superiores a $98 \%$. En consecuencia a lo anterior, el total de nutrientes y la energía digestibles a una vez mantenimiento, así como la concentración de energía neta para producción, fueron inferiores por el método biológico en las harinas de tortave y harina de carne y hueso y superior en la harina de pescado. Idéntico comportamiento se observó entre métodos al comparar los contenidos las energías netas para mantenimiento y crecimiento. Similares resultados encontraron Yu et al. (2004) al comparar el método biológico con los valores recomendados por el NRC (2001). Esto indica que la predictibilidad de la energía neta usando las fórmulas recomendadas por el NRC (2001) constituyen un método generalizado, apoyado en investigaciones realizadas principalmente por Weiss (1998) y Vermorel (1998). Sin embargo, los valores precisos de energía neta de los alimentos para producción de leche deben evaluarse por el método biológico (Smith et al. 1996). Con base en los requerimientos nutricionales del ganado de leche (NRC 2001), las tres materias primas evaluadas califican como fuentes energéticas para vacas con niveles altos de producción de leche, particularmente la harina de tortave es sobresaliente, en niveles de inclusión aún no estudiados. 
Las materias primas de origen animal se reconocen como fuentes de proteína a incluir con limitaciones en los alimentos balanceados (Jurgens 2004). Los resultados obtenidos permiten contrastar el contenido proteico de cada materia prima, por la cinética de degradación ruminal en cada una de ellas y el aprovechamiento cuantitativo dentro del animal. Al comparar el porcentaje de proteína indegradada en el rumen, contra el porcentaje de proteína contenida en la fracción C (insoluble e indegradable) del alimento, se percibe que la proteína sobrepasante y adicionalmente aprovechable por el animal en el tracto intestinal (PID - C) es de $2,68 \%$ en la harina de pescado y de $8,24 \%$ en la harina de carne y hueso, mientras que en la harina de tortave es de $19,79 \%$. Con estos resultados, los contenidos de proteína cruda efectiva en los alimentos, aquella realmente retenida por el animal en el proceso de digestión total, es de $53,29,51,86$ y $42,05 \%$, en base a materia seca, para la harina de pescado, harina de carne y hueso y la harina de tortave, con un residuo insoluble e indigerido, a eliminarse por las heces, de 1,47, 4,66 y $10,38 \%$, respectivamente en cada materia prima. El NRC (2001) no tiene disponibles valores de proteínas indigeribles e insolubles que permitan comparar los resultados. En la actualidad se busca mayor precisión en las ecuaciones de predicción de la digestibilidad de la materia seca y de las proteínas, a partir de la concentración de nutrientes (Yan et al. 2004), debido a los requerimientos de animales fistulados para emplear el método biológico (Agnew 2000).

\section{CONCLUSIONES Y RECOMENDACIONES}

Las materias primas de origen animal estudiadas, mostraron características propias de la especie fuente del subproducto, al observar tanto el valor de la fracción soluble como las velocidades de desaparición ruminal de la fracción potencialmente degradable.

El contenido total de nutrientes digeribles y los valores de energía digestible y neta de los alimentos fueron más reales al determinarse por el método biológico que por el método químico.

Los valores de energía neta para producción y los contenidos de proteína cruda efectivamente aprovechables por los animales fueron altos, lo que permite tipificar a la harina de pescado, la harina carne y hueso como fuentes proteicas con alto contenido de energía, recomendable para cubrir los requerimientos de ambos nutrientes en vacas lecheras de alta producción.
Con los resultados obtenidos se recomienda estudiar el grado de inclusión de cada materia prima en las mezclas balanceadas, para hace más efectiva la utilización de la proteína y energía contenida.

\section{LITERATURA CITADA}

AGNEW, R.E. 2000. The impact of recent research on energy feeding system for dairy cattle. Livestock Production Science 66:197-215.

A.O.A.C. (Association of Official Analysis Chemistry). 2002. Animal Feeds, Chapter 4. Washington D.C. USA. p. 1-6.

GARRETT, W.N. 1980. Energy utilization by growing cattle as determined by 72 comparative slaughter experiments. Energy Metabolism Proceeding Symposium 26:3-7.

GILL, J.L. 1978. Design and analysis of experiments in the animal and medical sciences. Iowa State University Press. Volume 1. p. 409.

JURGENS, M.H. 2002. Animal feeding and nutrition. Ninth Edition. Iowa State University. Kendall/Hunt Publishing Company. p. 588.

N.R.C. (National Research Council). 1989. Nutrient requirements of dairy cattle. Sixth revised edition. National Academy Press. USA. p. 157.

N.R.C. (National Research Council). 2001. Nutrient requirements of dairy cattle. Seventh revised edition. National Academy Press. USA. p. 381.

ORSKOV, E.R. 1984. Evaluation of residues and agroindustrial by-products using the nylon bag method. FAO-ILCA Publication. Roma, Italia. p. 128.

ORSKOV, E.R.; McDONALD. 1979. The estimation of protein degradability in the rumen from incubation measurements weighted according to the rate of passage. Journal of Agricultural Science 92: 499.

PICCIONI, M. 1970. Diccionario de alimentación animal. Editorial Acribia. Zaragoza, España. p. 819.

ROJAS, S.W. (1971) Nutrición animal. Escuela de Graduados ICA - UN. Universidad Nacional Agraria La Molina. Perú. p.289.

SAS. 1985. Statistical analysis system. User's guide: Statistics. 5 ed. SAS Institute Inc. Carry, NC. USA. p. 57. 
SMITH, M.E.; HANIGAN, M.D.; WEAKLY, D. C. 1996, Dairy energy system: goals, present status, and future directions. Journal of Dairy Science 79: (1):196.

VERMOREL, M.; COULON, J.B. 1998. Comparison of the National Research Council energy system for lactating cows with four european systems. Journal of Dairy Science 81:846-855.

WEISS, W.P. 1998. Estimating the available energy content of feeds for dairy cattle. Journal of Dairy Science 81:830839.
YAN, T.; AGNEW, R.E. 2004. Prediction of value in grass silage: II. Degradability of nitrogen and dry matter using digestibility, chemical composition, and fermentation data. Journal of Animal Science 82:1380-1391.

YU, P; CHISTIANSEN, D.A.; McKINNON, J.J.; SOITA, H.W. 2004. Using chemical and biological approaches to predict energy value of selected forages affected by variety and maturity stage: comparison of three approaches. Asian-Australasian Journal of Animal Sciences 17:228-236. 